\title{
Body image mediates the relationship between post-surgery needs and health- related quality of life among women with breast cancer: a cross-sectional study
}

\author{
Kaina Zhou, Wen Wang, Minjie Li, Jinghua An, Lanting Huo, Xiaole He, Jin Li and Xiaomei Li (D)
}

\begin{abstract}
Background: Although body image (BI) disturbance is a common problem that often contributes to poor healthrelated quality of life (HRQoL) among women with breast cancer following surgery, the mediating role of BI (as a self-perceptive factor) in the relationship between needs and HRQoL after controlling for socio-demographic factors remains unclear. The purpose of this study was to identify the mediating role of Bl between post-surgery needs and HRQoL after controlling for socio-demographic factors among women with breast cancer.

Methods: In this cross-sectional study, the primary outcome was HRQoL (as measured with the 36-item Short-Form Health Survey version 2 [SF-36v2] and Functional Assessment of Cancer Therapy-Breast version 4.0 [FACT-Bv4.0]). The secondary outcomes included needs (measured in terms of needs importance [NI] and needs satisfaction [NS]) and BI. Structural equation modeling was used to identify the mediating role of BI between needs and HRQoL while considering socio-demographics.

Results: The 406 eligible patients reported poor HRQoL, and approximately half reported important unmet needs and poor BI. NI, NS, and socio-demographics had differing direct effects on Bl and HRQoL, and contrasting indirect effects on HRQoL via BI. NI, NS, surgery type, presence of chronic disease, and BI explained $4 \%$ of the variance in the SF-36v2 physical component summary score; NI, NS, surgery type, residence, and BI explained 20\% of the variance in the mental component summary score; and NI, NS, marital status, employment status, radiotherapy, and $\mathrm{BI}$ explained 33\% of the variance in the FACT-Bv4.0 total score.

Conclusions: After surgery, women with breast cancer have poor HRQoL and BI, and important unmet needs. BI mediates the relationship between needs and HRQOL after controlling for socio-demographics. The present findings provide information for developing comprehensive Bl-based needs interventions and preparing targeted healthmanagement programs for patients with breast cancer.
\end{abstract}

Keywords: Breast cancer, Needs, Body image, Health-related quality of life, China

\footnotetext{
* Correspondence: roselee@xjtu.edu.cn

School of Nursing, Xi'an Jiaotong University Health Science Centre, No. 76

Yanta West Road, Xi'an 710061, Shaanxi, China
}

(c) The Author(s). 2020 Open Access This article is licensed under a Creative Commons Attribution 4.0 International License, which permits use, sharing, adaptation, distribution and reproduction in any medium or format, as long as you give appropriate credit to the original author(s) and the source, provide a link to the Creative Commons licence, and indicate if changes were made. The images or other third party material in this article are included in the article's Creative Commons licence, unless indicated otherwise in a credit line to the material. If material is not included in the article's Creative Commons licence and your intended use is not permitted by statutory regulation or exceeds the permitted use, you will need to obtain permission directly from the copyright holder. To view a copy of this licence, visit http://creativecommons.org/licenses/by/4.0/. The Creative Commons Public Domain Dedication waiver (http://creativecommons.org/publicdomain/zero/1.0/) applies to the data made available in this article, unless otherwise stated in a credit line to the data. 


\section{Background}

As surgery is the primary modality for breast cancer treatment, the majority of post-surgery patients experience body image (BI; i.e., one's perspective of his/her own body) disturbance and impaired health-related quality of life (HRQoL), which might subsequently require changes in one's capacity to cope with the illness $[1,2]$. According to Doyal and Gough, a need is a lack of something that is required or desired, and unsatisfied needs have been known to cause psychological distress [3]. However, due to varying socio-demographic characteristics and needs, patients might react differently to BI disturbances and experience different levels of HRQoL impairment [4]. Thus, the change in patients' needs during the disease course is a critical issue that requires the attention of health care providers. Given that sociodemographic features can be difficult to change, it is more critical to focus on needs (particularly their importance and satisfaction) for such patients in order to provide further information for the development of relevant interventions.

Although BI disturbance is a common problem that often induces poor HRQoL among women with breast cancer following surgery [5], the mediating role of BI (as a self-perceptive factor) in the relationship between needs and HRQoL (after controlling for sociodemographic characteristics) remains unclear. Since a positive BI and met needs are related to improved HRQoL [6], it is worthwhile to identify the influencing path between needs and HRQoL via BI. If BI does play a mediating role, needs-oriented interventions that consider BI might be used for post-surgery health improvement among women with breast cancer.

We, therefore, aimed to clarify the mediating role of $\mathrm{BI}$ in the relationship between post-surgery needs (i.e., their importance and satisfaction) and HRQoL, after controlling for the influence of potentially related socio-demographic factors among women with breast cancer. Two hypotheses were developed: (a) patients with different needs and sociodemographics would experience varying levels of BI and HRQoL impairment, and (b) BI would mediate the relationship between needs and HRQoL after controlling for the influence of socio-demographic characteristics. Our findings should provide valuable information for planning target intervention programs regarding health and BI management among this population.

\section{Methods}

Study design

A cross-sectional approach was adopted.

\section{Participants and data collection}

All participants were women with breast cancer who had been admitted to one of two hospitals in Xi'an following surgery. The patients were recruited via convenience sampling. Patients who were 18 years or above and spoke Chinese were included. However, patients who had other breast diseases, cognitive disorders (which were screened by a psychiatrist based on criteria of the Diagnostic and Statistical Manual of Mental Disorders, 5th ed.), or other chronic diseases (e.g., endocrine, cardiovascular, pneumonia, or infectious disease), and refused to provide written informed consent were excluded.

To ensure this cross-sectional study was impactful, we estimated the required sample size using the metric of 5 to 10 participants per item in the questionnaire survey [7]. Of the questionnaires used in the study, the instruments with the most items (i.e., 36 items) were the 36item Short-Form Health Survey version 2 (SF-36v2) and the Functional Assessment of Cancer Therapy-Breast version 4.0 (FACT-Bv4.0). Thus, the estimated sample size was 180 to 360 patients. However, anticipating sample loss, we enlarged the estimated sample size by $20 \%$ [7]. Consequently, the final sample size estimation was 216 to 432 participants.

Data collection was conducted from March to October 2018. The questionnaires were completed by the recruited patients within 6 months after surgery; patients with reading or writing difficulties were interviewed by trained data collectors who recorded the patients' responses.

\section{Measurements}

The primary outcome was HRQoL, which was measured using the SF-36v2 (a generic instrument) and the FACTBv4.0 (a disease-specific instrument). The secondary outcomes included BI, which was assessed using the Body Image Self-Rating Questionnaire for Breast Cancer (BISQ-BC), and needs, which were measured with the Needs Self-Rating Questionnaire for Breast Cancer (NSQ-BC). In this study, BI was considered as a potential mediating variable in the relationship between needs and HRQoL.

\section{SF-36v2}

The Chinese 36-item SF-36v2 was provided by QualityMetric Incorporated [8]. It comprises eight scales: physical function (PF), role-physical (RP), bodily pain (BP), general health $(\mathrm{GH})$, vitality (VT), social function (SF), role-emotional (RE), and mental health $(\mathrm{MH})$. These, in turn, form two summary components: the physical component summary (PCS) and the mental component summary (MCS). All scores were calculated using Health Outcomes Scoring Software 2.0 (QualityMetric 
Table 1 Patient characteristics $(N=406)$

\begin{tabular}{|c|c|}
\hline Characteristics & $n(\%)$ \\
\hline \multicolumn{2}{|l|}{ Socio-demographics } \\
\hline Age (years) (mean \pm SD) (range: $22-75)$ & $49.77 \pm 9.57$ \\
\hline \multicolumn{2}{|l|}{ Education level } \\
\hline Primary and lower & $84(20.7)$ \\
\hline Secondary & $234(57.6)$ \\
\hline Tertiary & $88(21.7)$ \\
\hline \multicolumn{2}{|l|}{ Marital status } \\
\hline Married & $387(95.3)$ \\
\hline Other & $19(4.7)$ \\
\hline \multicolumn{2}{|l|}{ Employment status } \\
\hline Employed & $152(37.4)$ \\
\hline Unemployed & $160(39.4)$ \\
\hline Retired & $94(23.2)$ \\
\hline \multicolumn{2}{|c|}{ Average monthly income over the past year (Chinese yuan) } \\
\hline$<1000$ & $100(24.6)$ \\
\hline $1000-3000$ & $174(42.9)$ \\
\hline$>3000$ & $132(32.5)$ \\
\hline \multicolumn{2}{|l|}{ Residence } \\
\hline Rural & $200(49.3)$ \\
\hline Urban & $206(50.7)$ \\
\hline \multicolumn{2}{|l|}{ Suffering from chronic disease(s) } \\
\hline Yes & 80 (19.7) \\
\hline No & $326(80.3)$ \\
\hline
\end{tabular}

\section{Clinical characteristics}

\begin{tabular}{ll} 
IIIness stage & $74(18.2)$ \\
I & $211(52.0)$ \\
II & $95(23.4)$ \\
IV & $26(6.4)$ \\
Morgery type & \\
Total mastectomy & $258(63.5)$ \\
Lumpectomy and axillary dissection & $99(24.4)$ \\
Breast conserving surgery & $37(9.1)$ \\
Chemotherapy & $12(3.0)$ \\
Yes & \\
No & $402(99.0)$ \\
Radiotherapy & $4(1.0)$ \\
Yes & \\
No & $46(11.3)$ \\
Endocrinotherapy & $360(88.7)$ \\
Yes & \\
No & $34(8.4)$ \\
\hline
\end{tabular}

Needs importance (NI) (mean \pm SD)
Table 1 Patient characteristics $(N=406)$ (Continued)

\begin{tabular}{ll}
\hline Characteristics & $\boldsymbol{n}(\%)$ \\
\hline Respect/self-esteem needs (RSE) & $76.38 \pm 12.44$ \\
Rehabilitation needs (REH) & $73.61 \pm 13.57$ \\
Information needs (INF) & $71.54 \pm 13.74$ \\
Physical needs (PHY) & $65.83 \pm 17.84$ \\
Psychological needs (PSY) & $58.43 \pm 19.58$ \\
Needs satisfaction (NS) (mean \pm SD) & \\
Respect/self-esteem needs (RSE) & $69.73 \pm 12.49$ \\
Rehabilitation needs (REH) & $59.30 \pm 16.09$ \\
Physical needs (PHY) & $55.99 \pm 17.24$ \\
Information needs (INF) & $52.66 \pm 16.84$ \\
Psychological needs (PSY) & $51.44 \pm 18.22$ \\
Body image (BI) (mean \pm SD) & \\
Bl-related behavior change (BI-BC) & $62.76 \pm 14.83$ \\
Bl-related self-cognition change (BI-SCo) & $59.04 \pm 13.33$ \\
Bl-related arm change (BI-AC) & $58.50 \pm 11.93$ \\
Bl-related psychological change (BI-PC) & $53.76 \pm 16.72$ \\
Bl-related sexual activity change (BI-SAC) & $52.83 \pm 16.18$ \\
Bl-related social change (BI-SC) & $52.03 \pm 23.66$ \\
Bl-related role change (BI-RC) & $50.03 \pm 17.18$
\end{tabular}

36-item Short Form Health Survey version 2.0 (SF-36v2) (mean \pm SD)

Physical component summary (PCS)
Mental component summary (MCS)
Physical functioning (PF)
Role-physical (RP)
Bodily pain (BP)
General Health (GH)
Vitality (VT)
Social functioning (SF)
Role-emotional (RE)
Mental health (MH)

$43.72 \pm 6.15$

$42.23 \pm 9.09$

$45.54 \pm 6.51$

$34.85 \pm 9.69$

$47.53 \pm 9.89$

$42.72 \pm 8.89$

$48.75 \pm 8.36$

$39.15 \pm 10.53$

$38.59 \pm 10.70$

$44.12 \pm 8.25$

\section{Functional Assessment of Cancer Therapy-Breast version 4.0} (FACT-Bv4.0) (mean \pm SD)

$\begin{array}{ll}\text { Physical well-being (PWB) } & 17.72 \pm 5.07 \\ \text { Social/family well-being (SWB) } & 18.46 \pm 4.75 \\ \text { Emotional well-being (EWB) } & 17.10 \pm 4.34 \\ \text { Functional well-being (FWB) } & 13.59 \pm 5.42 \\ \text { Breast cancer specific additional concerns (BCS) } & 21.84 \pm 5.09 \\ \text { Total score } & 88.71 \pm 17.25\end{array}$

$S D$ standard deviation

Incorporated) based on norms, with a mean of 50 and a standard deviation of 10 [9]. For all scales and summary components, higher scores indicated better HRQoL. For this study, the Cronbach's $\alpha$ was 0.91 . 


\section{FACT-Bv4.0}

The 36-item Chinese FACT-Bv4.0 includes a general subscale (FACT-G) consisting of physical well-being (PWB), social/family well-being (SWB), emotional wellbeing (EWB), and functional well-being (FWB), and a subscale measuring breast-cancer-specific additional concerns (BCS) [10]. Each item was rated using a fivepoint Likert scale (from 0 to 4 ), with a total score ranging from 0 to 144. A higher score indicated better HRQoL [11]. The Chinese FACT-Bv4.0 has been found to have satisfactory psychometrics among breast cancer patient populations [10]. For this study, the Cronbach's $\alpha$ was 0.88 .

\section{$B I S Q-B C$}

The 33-item BISQ-BC was developed by the authors, including subscales on BI-related self-cognition (BI-SCo), BI-related behavior change (BI-BC), BI-related arm change (BI-AC), BI-related sexual activity change (BI$\mathrm{SAC})$, BI-related role change (BI-RC), BI-related psychological change (BI-PC), and BI-related social change (BISC) [12]. Each item was rated using a five-point Likert scale $(1=$ strongly disagree to $5=$ strongly agree $)$. All scores were standardized using the following formula: ([actual score - the lowest possible score]/ [the highest possible score - the lowest possible score]) $\times 100$ [13] . All standardized scores ranged from 0 to 100 , with higher scores representing worse BI. For this study, the Cronbach's $\alpha$ was 0.86 .
NSQ-BC

The authors also developed the 28-item NSQ-BC based on a review of existing empirical literature regarding the needs of Chinese women with breast cancer, which examined their physical needs (PHY), psychological needs (PSY), respect/self-esteem needs (RSE), information needs (INF), and rehabilitation needs (REH) [14]. Based on the needs assessment and intervention outcome evaluation, the authors divided the NSQ-BC into the following dimensions: Needs Importance (NI; for needs assessment, i.e., whether a given need is the most needed or desired one) and Needs Satisfaction (NS; for intervention outcome evaluation; i.e., whether a given need has been fully met) dimensions for this questionnaire. For a more detailed understanding of the NSQ-BC, please see a previously published study [14]. Each item was rated using a five-point Likert format $(1=$ not important/satisfied to $5=$ very important/satisfied). The scale and total scores were standardized using the same formula as the BISQ-BC [13]. All standardized scores ranged from 0 to 100 , with higher scores indicating higher levels of NI and NS. For this study, the Cronbach's $\alpha$ was 0.73 (NI) and $0.71(\mathrm{NS})$.

\section{Data analyses}

An independent samples $t$-test was applied to compare $\mathrm{BI}$ and HRQoL between patients with different levels of NI and NS, and to compare HRQoL among patients with different levels of BI disturbance. Meanwhile, a

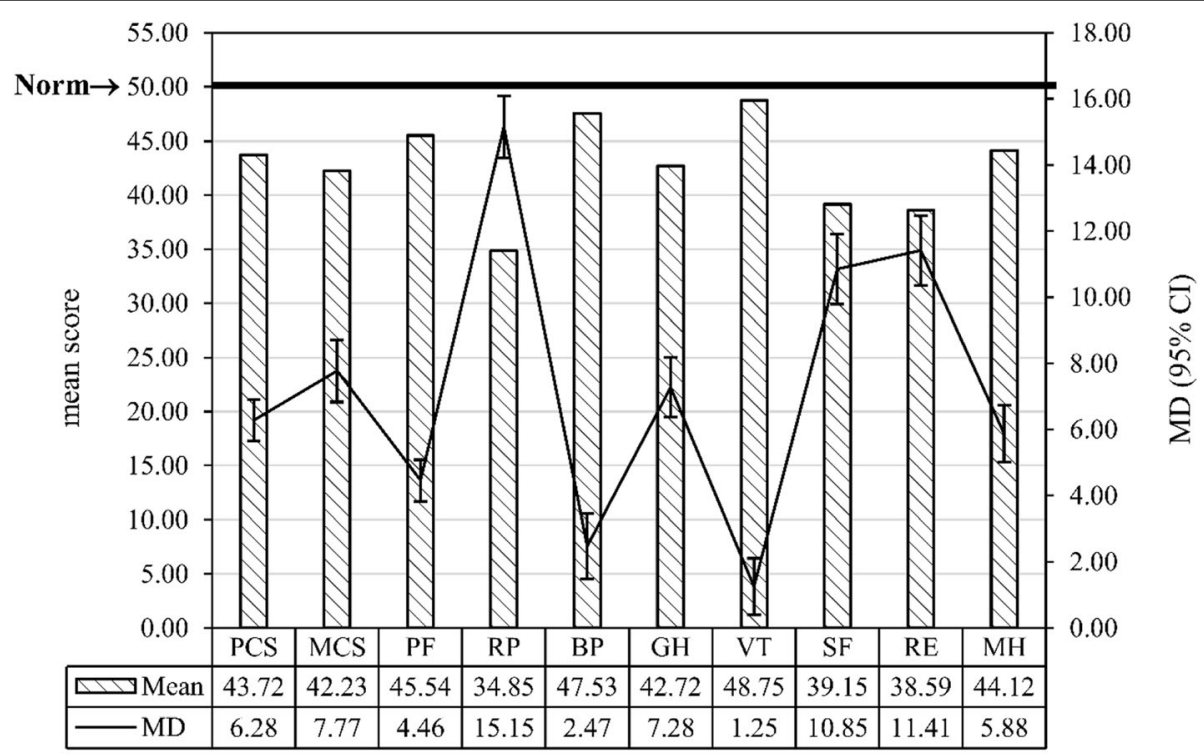

SF-36v2: two summary components and eight scales

Fig. 1 Scores on the two summary components and eight scales of the SF-36v2 Health Survey. MD: mean difference between the scores and the norm with 95\% confidence intervals (CI); SF-36v2: Short-Form 36 Health Survey version 2; PCS: physical component summary; MCS: mental component summary; PF: physical functioning; RP: role-physical; BP: bodily pain; GH: general health; VT: vitality; SF: social functioning; RE: rolephysical; $\mathrm{MH}$ : mental health 
one-sample $t$-test was used to compare patients' SF-36v2 scores with the norm score $($ mean $=50)$. A multiple linear stepwise regression analysis was performed to identify the significant influencing factors of BI and HRQoL.

Structural Equation Modeling (SEM) is a method for building, estimating, and testing theoretical models of the relationships between variables. It can be used in lieu of multiple regression and other methods to analyze the strength of the correlations between individual variable indicators within a given population [15]. In this study, the previously determined significant factors were used in SEM to identify the mediating role of $\mathrm{BI}$ on the relationship between NI, NS, socio-demographic factors, and HRQoL. Standardized direct, indirect, and total effects with corresponding 95\% bias-corrected confidence intervals were measured using the bootstrapping method $[15,16]$.

The mediating effect was examined by determining whether (i) the independent variables had significant direct effects on the mediator (i.e., the factor with mediating roles between certain variables); (ii) the independent variables had significant direct effects on the outcome variable; and (iii) the independent variables had significant indirect effects, and the mediator had significant direct effects, on the outcome variable [17].

The model fit was tested using the normed chi-square (NC; desired value $<2.0), X^{2}$ value (desired significance $P>0.05$ ), goodness-of-fit index (GFI; desired value>

Table 2 Mean differences in BI, SF-36v2, and FACT-Bv4.0 according to NI, NS, and BI scores ( $\mathrm{N}=406)$

\begin{tabular}{|c|c|c|c|c|c|c|}
\hline & \multicolumn{2}{|c|}{$\begin{array}{l}\text { Needs importance (NI) ( } \leq 69 \text { vs. } \\
>69 \text { ) }\end{array}$} & \multicolumn{2}{|c|}{$\begin{array}{l}\text { Needs satisfaction (NS) ( } \leq 55 \text { vs. } \\
>55 \text { ) }\end{array}$} & \multicolumn{2}{|l|}{$\mathrm{BI}(\leq 56 \mathrm{vs} .>56)$} \\
\hline & $\mathrm{MD}(95 \% \mathrm{Cl})$ & $P$ & $\mathrm{MD}(95 \% \mathrm{Cl})$ & $P$ & $\mathrm{MD}(95 \% \mathrm{Cl})$ & $P$ \\
\hline \multicolumn{7}{|l|}{ Body image (BI) } \\
\hline Self-cognition (SCO) & $-2.09(-4.69,0.52)$ & 0.12 & $-1.45(-4.05,1.15)$ & 0.28 & - & - \\
\hline Behavior change (BC) & $-2.48(-5.37,0.42)$ & 0.09 & $3.13(0.25,6.01)$ & 0.03 & - & - \\
\hline Arm change (AC) & $-0.68(-3.02,1.65)$ & 0.57 & $-2.05(-4.37,0.27)$ & 0.08 & - & - \\
\hline Sexual activity change (SAC) & $-2.19(-5.35,0.98)$ & 0.18 & $6.84(3.75,9.93)$ & $<0.001$ & - & - \\
\hline Role change (RC) & $-2.54(-5.90,0.81)$ & 0.14 & $3.80(0.46,7.13)$ & 0.026 & - & - \\
\hline Psychological change (PC) & $-1.44(-4.71,1.83)$ & 0.39 & $9.32(6.19,12.46)$ & $<0.001$ & - & - \\
\hline Social change (SC) & $-2.14(-6.77,2.49)$ & 0.37 & $7.39(2.82,11.96)$ & 0.002 & - & - \\
\hline Body image total score & $-2.00(-4.17,0.17)$ & 0.07 & $4.25(2.11,6.38)$ & $<0.001$ & - & - \\
\hline \multicolumn{7}{|l|}{ SF-36v2 } \\
\hline Physical function (PF) & $0.97(-0.29,2.23)$ & 0.13 & $1.14(-0.11,2.39)$ & 0.07 & $1.19(-0.07,2.44)$ & 0.06 \\
\hline Role-physical (RP) & $1.30(-0.54,3.15)$ & 0.17 & $0.85(-0.99,2.70)$ & 0.36 & $4.22(2.42,6.02)$ & $<0.001$ \\
\hline Bodily pain (BP) & $4.18(2.24,6.12)$ & $<0.001$ & $1.78(-0.19,3.75)$ & 0.08 & $0.74(-1.24,2.72)$ & 0.46 \\
\hline General health $(\mathrm{GH})$ & $0.90(-0.93,2.72)$ & 0.33 & $-2.06(-3.88,-0.25)$ & 0.026 & $5.28(3.53,7.03)$ & $<0.001$ \\
\hline Vitality (VT) & $-0.88(-2.60,0.85)$ & 0.32 & $-2.75(-4.45,-1.05)$ & 0.002 & $4.02(2.34,5.70)$ & $<0.001$ \\
\hline Social function (SF) & $3.19(1.08,5.31)$ & 0.003 & $1.36(-0.77,3.49)$ & 0.21 & $4.86(2.78,6.95)$ & $<0.001$ \\
\hline Role-emotional (RE) & $2.88(0.77,4.99)$ & 0.007 & $-0.10(-2.26,2.02)$ & 0.92 & $5.90(3.85,7.94)$ & $<0.001$ \\
\hline Mental health $(\mathrm{MH})$ & $1.44(-0.29,3.17)$ & 0.10 & $-2.80(-4.51,-1.09)$ & 0.001 & $5.52(3.87,7.17)$ & $<0.001$ \\
\hline Physical component summary (PCS) & $1.50(0.23,2.77)$ & 0.021 & $-1.38(-2.65,-0.11)$ & 0.033 & $1.27(-0.005,2.53)$ & 0.05 \\
\hline Mental component summary (MCS) & $1.80(-0.09,3.68)$ & 0.06 & $-2.19(-4.07,-0.32)$ & 0.022 & $6.55(4.77,8.33)$ & $<0.001$ \\
\hline \multicolumn{7}{|l|}{ FACT-Bv4.0 } \\
\hline Physical well-being (PWB) & $0.64(-0.36,1.64)$ & 0.21 & $-1.05(-2.04,-0.06)$ & 0.038 & $3.17(2.22,4.12)$ & $<0.001$ \\
\hline Social/family well-being (SWB) & $-2.11(-3.43,-0.80)$ & 0.002 & $-2.53(-3.84,-1.23)$ & $<0.001$ & $1.59(0.26,2.92)$ & 0.019 \\
\hline Emotional well-being (EWB) & $0.66(-0.21,1.53)$ & 0.14 & $-2.35(-3.19,-1.51)$ & $<0.001$ & $3.52(2.71,4.32)$ & $<0.001$ \\
\hline Functional well-being (FWB) & $-1.27(-2.31,-0.24)$ & 0.016 & $-2.36(-3.38,-1.35)$ & $<0.001$ & $2.39(1.38,3.40)$ & $<0.001$ \\
\hline Additional breast cancer-specific concerns (BCS) & $1.81(0.83,2.79)$ & $<0.001$ & $-0.94(-1.92,0.05)$ & 0.06 & $4.21(3.30,5.11)$ & $<0.001$ \\
\hline FACT-Bv4.0 total score & $-2.10(-6.99,2.78)$ & 0.40 & $-9.90(-14.61,-5.20)$ & $<0.001$ & $12.86(8.32,17.40)$ & $<0.001$ \\
\hline
\end{tabular}

Significant results are presented in bold. Needs importance, needs satisfaction, and BI were grouped by the corresponding median score

"-" signifies no value

MD mean difference, 95\% Cl 95\% confidence interval 
0.90), adjusted GFI (AGFI; desired value> 0.90), and root mean square error of approximation (RMSEA; desired value $<0.08)$ [15].

The database was built using Epidata 3.1. Two data managers double-entered the data to minimize the risk of data-entry errors. The data were analyzed using SPSS Statistics 23.0 and AMOS 23.0, and values of $P<0.05$ (two-tailed) were considered statistically significant.

\section{Ethics statement}

The study protocol was approved by the Biomedical Ethics Committee of Xi'an Jiaotong University Health Science Center (Reference No.: 2015-170). Informed consent was obtained from all participants in the study.

\section{Results}

Among the 430 recruited patients, 406 (94.4\%) completed the questionnaire survey. Of the 24 excluded patients, 15 had a history of chronic medical disorders, and 9 refused to provide written informed consent. Table 1 shows the detailed socio-demographic characteristics of the participants.

\section{$\mathrm{NI}, \mathrm{NS}, \mathrm{BI}$, and HRQoL}

The mean NI score was $68.87 \pm 12.66$ (range: $23-100$ ); $46.6 \%(n=189)$ of the patients considered their needs as important (median score $>69$ ). The mean NS score was
$56.99 \pm 14.11$ (range: $22-100) ; 50 \%(n=203)$ of the patients considered their needs to be unsatisfied (median score $\leq 55)$. The respect/self-esteem needs scale score was highest for both the NI and NS dimensions (Table 1).

The total mean BI score was 55.84 \pm 11.13 (range: 14$90) ; 52.5 \%(n=213)$ of the patients reported poor BI (median score $>56)$. The BI-related behavior change scale $($ mean $=62.76 \pm 14.83)$ had the highest score (Table 1$)$.

Regarding the SF-36v2, the two summary components and the eight scale scores were all lower than the normed score $(P<0.05)$. The overall psychological health (mean difference in MCS: 7.77) was lower than the overall physical health (mean difference in PCS: 6.28; Fig. 1). The mean FACT-Bv4.0 total score was $88.71 \pm 17.25$ (range: $33-127)$. The BCS score $($ mean $=22.27 \pm 5.04)$ was the highest among the FACT-Bv4.0 subscales (Table 1).

NI, NS, and socio-demographics concerning BI and HRQoL Patients with lower NI scores (i.e., median score $\leq 69)$ had higher scores on the SF-36v2 and FACT-Bv4.0 $(P<$ 0.05 ), while patients with lower NS scores (i.e., median score $\leq 55$ ) had higher scores on the BISQ-BC and lower scores on the SF-36v2 and FACT-Bv4.0 $(P<0.05)$. Moreover, patients with lower BISQ-BC scores (i.e., median score $\leq 56)$ had higher scores on the SF-36v2 and FACTBv4.0 $(P<0.05$; Table 2$)$.

Table 3 Predictors of body image, PCS, MCS, and FACT-Bv4.0 scores: multiple linear stepwise regression analysis ${ }^{\dagger}(N=406)$

\begin{tabular}{|c|c|c|c|c|}
\hline Dependent variable & Independent variables & $\mathrm{B}(95 \% \mathrm{Cl})$ & $P$ & $\mathrm{VIF}^{\dagger}$ \\
\hline \multirow[t]{3}{*}{ Body image $^{a}$} & Needs satisfaction & $-0.34(-0.36,-0.18)$ & $<0.001$ & 1.02 \\
\hline & Needs importance & $0.30(0.17,0.36)$ & $<0.001$ & 1.01 \\
\hline & Lumpectomy and axillary dissection (ref. modified radical mastectomy) & $-0.11(-7.80,-0.54)$ & 0.025 & 1.06 \\
\hline \multirow[t]{3}{*}{$P C S^{b}$} & Body image & $-0.12(-0.13,-0.01)$ & 0.019 & 1.05 \\
\hline & Needs importance & $-0.11(-0.10,-0.007)$ & 0.026 & 1.03 \\
\hline & Chronic disease (ref. yes) & $0.10(0.03,3.21)$ & 0.045 & 1.03 \\
\hline \multirow[t]{3}{*}{$\mathrm{MCS}^{\mathrm{C}}$} & Body image & $-0.40(-0.42,-0.27)$ & $<0.001$ & 1.02 \\
\hline & Residence (ref. rural) & $0.14(1.03,4.49)$ & 0.002 & 1.02 \\
\hline & Lumpectomy and axillary dissection (ref. modified radical mastectomy) & $-0.10(-6.49,-0.50)$ & 0.022 & 1.05 \\
\hline \multirow[t]{5}{*}{ FACT-Bv4. $0^{d}$} & Body image & $-0.42(-0.80,-0.44)$ & $<0.001$ & 1.03 \\
\hline & Unemployed (ref. employed) & $-0.21(-11.68,-3.45)$ & $<0.001$ & 1.05 \\
\hline & Needs satisfaction & $0.16(0.06,0.37)$ & 0.008 & 1.02 \\
\hline & Radiotherapy (ref. yes) & $0.13(0.69,12.06)$ & 0.028 & 1.05 \\
\hline & Marital status (ref. married) & $-0.13(-22.80,-1.02)$ & 0.032 & 1.05 \\
\hline
\end{tabular}

Multiple linear stepwise regression analysis was performed after controlling for the following dummy variables: education level (ref. primary and below), marital status (ref. married), employment status (ref. employed), average monthly income over the past year (Chinese yuan, ref. < 1000), residence (ref. rural), chronic disease (ref. yes), illness stage (ref. 0-l), surgery type (ref. modified radical mastectomy), chemotherapy (ref. yes), radiotherapy (ref. yes), and endocrinotherapy (ref. yes), as well as continuous characteristics (age, body image, psychosocial needs importance, and psychosocial needs satisfaction)

Body image predictor model: $\mathrm{R}^{2}=0.11, F=15.72, P<0.001$

${ }^{b} \mathrm{PCS}$ predictor model: $\mathrm{R}^{2}=0.04, F=5.23, P=0.001$

${ }^{\mathrm{c}} \mathrm{MCS}$ predictor model: $\mathrm{R}^{2}=0.19, F=30.97, P<0.001$

${ }^{\mathrm{d}}$ FACT-Bv4.0 predictor model: $\mathrm{R}^{2}=0.35, F=20.37, P<0.001$

${ }^{+} \mathrm{VIF}<10$ indicates no significant multicollinearity

$95 \% \mathrm{Cl}$ : $95 \%$ confidence interval. VIF: variance inflation factor 
Table 4 Factors with standardized total/direct/indirect effects on BI, PCS, and MCS (N=406)

\begin{tabular}{|c|c|c|c|c|c|c|}
\hline \multirow[t]{2}{*}{ Predictor effects } & \multicolumn{2}{|l|}{ Body image (Bl, mediator) } & \multicolumn{2}{|c|}{ Physical component summary (PCS) } & \multicolumn{2}{|c|}{ Mental component summary (MCS) } \\
\hline & $\mathrm{B}(95 \% \mathrm{Cl})$ & $P$ & B $(95 \% C l)$ & $P$ & $\mathrm{~B}(95 \% \mathrm{Cl})$ & $P$ \\
\hline \multicolumn{7}{|l|}{ Total effects } \\
\hline Body image & - & - & $-0.115(-0.202,-0.003)$ & 0.047 & $-0.351(-0.434,-0.258)$ & 0.002 \\
\hline Needs importance & $0.297(0.195,0.397)$ & 0.002 & $-0.145(-0.245,-0.043)$ & 0.009 & $-0.254(-0.363,-0.136)$ & 0.003 \\
\hline Needs satisfaction & $-0.341(-0.455,-0.232)$ & 0.002 & $0.039(0.004,0.076)$ & 0.034 & $0.261(0.149,0.373)$ & 0.003 \\
\hline LAD (ref. MRM) & $-0.106(-0.214,-0.004)$ & 0.043 & $0.012(0.000,0.036)$ & 0.048 & $-0.052(-0.155,0.049)$ & 0.314 \\
\hline Chronic disease (ref. yes) & - & - & $0.100(0.004,0.206)$ & 0.040 & - & - \\
\hline Residence (ref. rural) & - & - & - & - & $0.150(0.050,0.236)$ & 0.002 \\
\hline \multicolumn{7}{|l|}{ Direct effects } \\
\hline Body image & - & - & $-0.115(-0.202,-0.003)$ & 0.047 & $-0.351(-0.434,-0.258)$ & 0.002 \\
\hline Needs importance & $0.297(0.195,0.397)$ & 0.002 & $-0.111(-0.211,-0.009)$ & 0.035 & $-0.150(-0.249,-0.037)$ & 0.004 \\
\hline Needs satisfaction & $-0.341(-0.455,-0.232)$ & 0.002 & - & - & $0.142(0.039,0.244)$ & 0.007 \\
\hline LAD (ref. MRM) & $-0.106(-0.214,-0.004)$ & 0.043 & - & - & $-0.089(-0.184,-0.002)$ & 0.043 \\
\hline Chronic disease (ref. yes) & - & - & $0.100(0.004,0.206)$ & 0.040 & - & - \\
\hline Residence (ref. rural) & - & - & - & - & $0.150(0.050,0.236)$ & 0.002 \\
\hline \multicolumn{7}{|l|}{ Indirect effects } \\
\hline Body image & - & - & - & - & - & - \\
\hline Needs importance & - & - & $-0.034(-0.066,-0.004)$ & 0.032 & $-0.104(-0.150,-0.065)$ & 0.001 \\
\hline Needs satisfaction & - & - & $0.039(0.004,0.076)$ & 0.034 & $0.120(0.077,0.173)$ & 0.001 \\
\hline LAD (ref. MRM) & - & - & $0.012(0.000,0.036)$ & 0.048 & $0.037(0.003,0.080)$ & 0.036 \\
\hline Chronic disease (ref. yes) & - & - & - & - & - & - \\
\hline Residence (ref. rural) & - & - & - & - & - & - \\
\hline
\end{tabular}

"_" signifies no value

LAD Lumpectomy and axillary dissection, MRM modified radical mastectomy, $95 \% \mathrm{Cl} 95 \%$ confidence interval

Since BI (BISQ-BC total score) is the mediator, it was regarded as either the independent or dependent variable. The findings showed that NI and NS had significant influences on BI and HRQoL, while BI had a significant influence on HRQoL (Table 3). Therefore, BI could be considered a mediator between NI/NS and HRQoL.

In the PCS, MCS, and FACT-Bv4.0 models, NI, NS, and socio-demographics had significant direct effects on BI or HRQoL, and significant indirect effects on HRQoL via BI. As for total effects, NI, NS, marital status, employment status, radiotherapy, and $\mathrm{BI}$ explained the most variance (33\%) in HRQoL (FACT-Bv4.0; Tables 4 and 5, Fig. 2).

\section{Discussion}

Interestingly, the needs ordering (in terms of NI and NS) regarding the patients were not very consistent. The two primary needs (i.e., respect/self-esteem and rehabilitation needs) indicate that patients received requisite acceptance and care from health professionals and family members. However, the most commonly important unsatisfied need was information, further indicating that information is one of the most critical support sources during treatment and rehabilitation [18-20]. It suggests that improving access to information must be seriously considered via target interventions. Physical needs were the fourth in NI, but third in NS, which is probably due to improvements in treatment modalities and post-operative nursing programs. The final psychology need reflects that patients were probably neglecting their psychological needs. Since unmet psychological needs are commonly reported [21], it is crucial to focus on patients' psychological health, enhance professional mental health care, and facilitate patients' self-care abilities.

Regarding BI-related changes (i.e., behavior, selfcognition, arm, psychological, sexual activity, social activity, and roles) in the BISQ-BC, the first three were seriously affected, and thus require careful observation following surgery. The remaining four should also be seriously assessed while planning programs for improving BI [22].

We found that NI probably does not affect BI disturbance. However, unmet needs are related to poorer BI. Previous studies have reported the influence of psychological distress, socio-demographics, and clinical factors on BI [4]; however, the influence of unmet needs on BI has rarely been explored. This means that while improving patients' $\mathrm{BI}$, the implementation of programs that enhance NS should also be carefully considered. 
Table 5 Factors with total, direct, and indirect effects on self-rated body image and FACT-Bv4.0: path analysis ( $N=406$ )

\begin{tabular}{|c|c|c|c|c|}
\hline \multirow[t]{2}{*}{ Predictor effects } & \multicolumn{2}{|l|}{ Body image (mediator) } & \multicolumn{2}{|l|}{ FACT-Bv4.0 } \\
\hline & B $(95 \% \mathrm{Cl})$ & $P$ & B $(95 \% \mathrm{Cl})$ & $P$ \\
\hline \multicolumn{5}{|l|}{ Total effects } \\
\hline Body image & - & - & $-0.432(-0.536,-0.324)$ & 0.001 \\
\hline Needs importance & $0.192(0.044,0.315)$ & 0.013 & $-0.083(-0.143,-0.022)$ & 0.008 \\
\hline Needs satisfaction & $-0.316(-0.470,-0.146)$ & 0.002 & $0.312(0.171,0.436)$ & 0.002 \\
\hline Marital status (ref. married) & - & - & $-0.132(-0.155,-0.009)$ & 0.032 \\
\hline Unemployed (ref. employed) & - & - & $-0.223(-0.371,-0.126)$ & 0.020 \\
\hline Radiotherapy (ref. yes) & - & - & $0.130(0.098,0.257)$ & 0.041 \\
\hline \multicolumn{5}{|l|}{ Direct effects } \\
\hline Body image & - & - & $-0.432(-0.536,-0.324)$ & 0.001 \\
\hline Needs importance & $0.192(0.044,0.315)$ & 0.013 & - & - \\
\hline Needs satisfaction & $-0.316(-0.470,-0.146)$ & 0.002 & $0.176(0.055,0.300)$ & 0.005 \\
\hline Marital status (ref. married) & - & - & $-0.132(-0.155,-0.009)$ & 0.032 \\
\hline Unemployed (ref. employed) & - & - & $-0.223(-0.371,-0.126)$ & 0.020 \\
\hline Radiotherapy (ref. yes) & - & - & $0.130(0.098,0.257)$ & 0.041 \\
\hline \multicolumn{5}{|l|}{ Indirect effects } \\
\hline Body image & - & - & - & - \\
\hline Needs importance & - & - & $-0.083(-0.143,-0.022)$ & 0.008 \\
\hline Needs satisfaction & - & - & $0.136(0.060,0.220)$ & 0.001 \\
\hline Marital status (ref. married) & - & - & - & - \\
\hline Unemployed (ref. employed) & - & - & - & - \\
\hline Radiotherapy (ref. yes) & - & - & - & - \\
\hline
\end{tabular}

The present findings revealed that patients with less $\mathrm{NI}$, more NS, and better BI have better HRQoL [1, 5, 21]. Thus, it appears critical to detect and meet patients' important needs following surgery; furthermore, BIrelated changes should be carefully assessed to plan target intervention programs for improving $\mathrm{BI}$, which would be beneficial for enhancing HRQoL.

Some socio-demographic factors were related to BI and HRQoL, suggesting that for BI and HRQoL care, treatment modalities (e.g., surgery type and adjuvant therapy), basic diseases (e.g., chronic diseases), and life status (e.g., residence, marital status, and employment status) should be seriously considered when planning individualized intervention programs $[23,24]$. Due to worry about the cancer recurrence, most Chinese mainland women with breast cancer would like to receive mastectomy, only a small proportion of patients would like to receive breast conservation surgery. Thus, whether breast conservation was associated with improved body image and quality of life in Chinese mainland women with breast cancer needs further study.

In the SEM analysis, BI was a significant mediator of the relationship between NI/NS and HRQoL. Additionally, BI was also a significant mediator between surgery type and HRQoL (measured by the SF-36v2), which further implies that BI should be regarded as an essential interventional factor when improving patients' health following surgery [5]. This finding supports the notion that BI could be affected by important unmet needs and undergoing radical mastectomy, which could lead to HRQoL impairments $[1,21]$. Therefore, post-surgery NI and NS should be regarded as important factors during the assessment and nursing-care process among women with breast cancer, especially those with BI disturbance.

From the treatment viewpoint, the benefits of using breast conservation surgery and breast reconstruction surgery, if permitted, should be provided to the patients, so that the two treatments could be more commonly pursued. Chemotherapy and endocrine therapy were not found to have significant effects on body image, which is probably due to only a small proportion of the patients who did not receive chemotherapy $(n=4,1 \%)$, or receive endocrine therapy $(n=34,8.4 \%)$. Thus, the explicit assumption that poor body image was the result of chemotherapy and endocrine therapy needs further examination.

In the SF-36v2, patients had significantly lower scores on the two summary components and the eight scales, reflecting poorer HRQoL than what has 
(a)
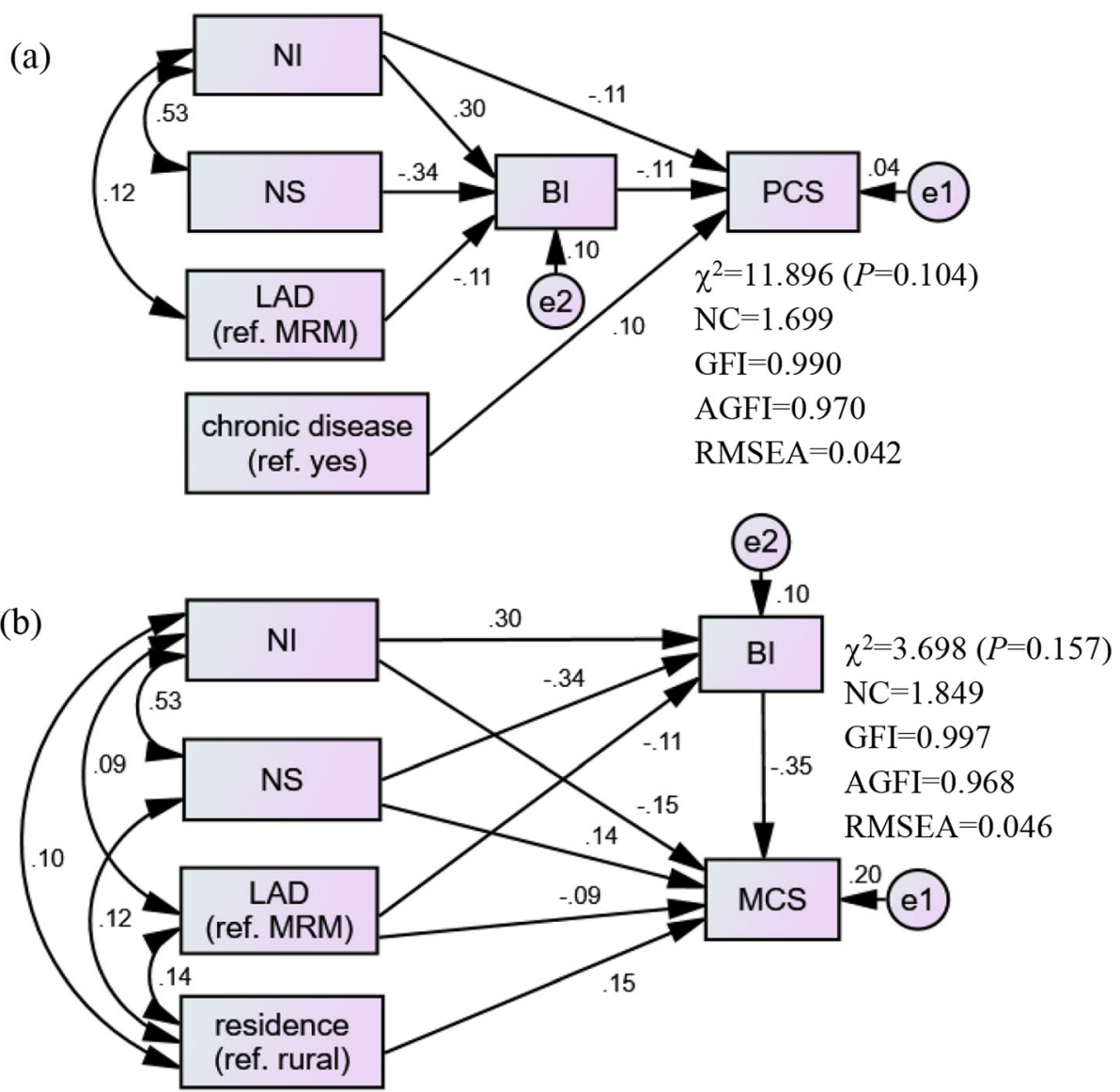

(c)

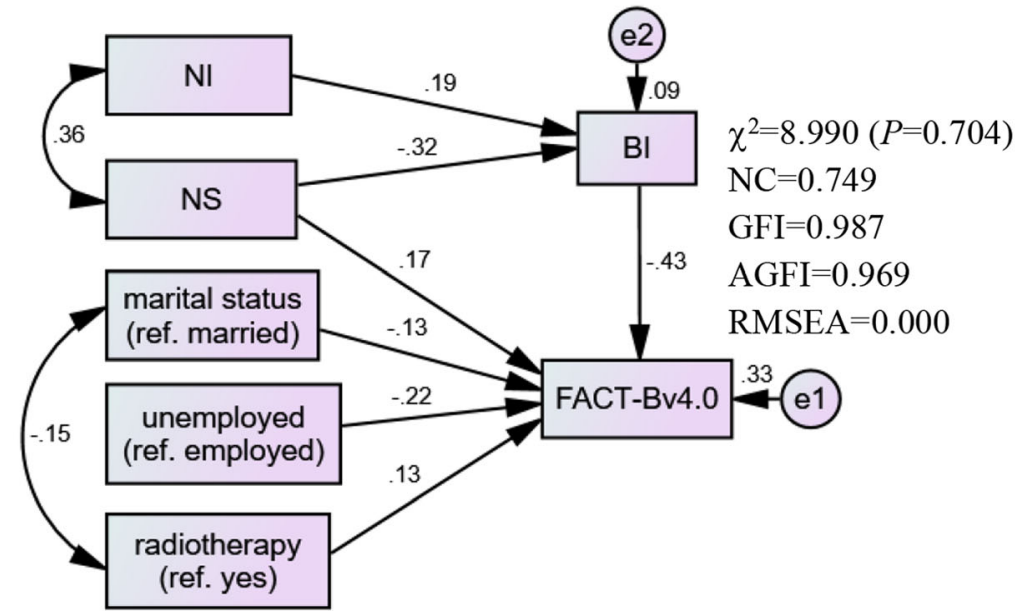

Fig. 2 Direct, indirect, and total effects of NI and NS on BI and HRQOL. NC=Normed Chi-square, <2.0; GFI=goodness-of-fit index, >0.90; AGFI= adjusted goodness-of-fit index, >0.90; RMSEA = root mean square error of approximation, < 0.08. LAD: lumpectomy and axillary dissection. MRM: modified radical mastectomy

been observed in the general population. Specifically, the FACT-Bv4.0 scores revealed that patients had few additional concerns in relation to breast cancer, but patients' functional, emotional, physical, and social/ family well-being were affected by the disease. These findings suggest the need for further efforts to improve HRQoL [24].

This study has several limitations. First, the needs, BI, and HRQoL data were based on self-reports and lacked objective indicators. Second, the missing data on post-surgery 
complications should be considered in our future study, since complications are potential influencing factors for HRQoL. Third, the subjective nature of the survey measures could have generated response biases. Hence, a prospective study may be required to appropriately explore the complex relationship between needs, BI, and HRQoL. Fourth, the cross-sectional design makes it impossible to state the temporality between the exposure and outcome variables. Finally, this study was only conducted in Xi'an, limiting the generalizability of our results among other patient samples.

\section{Conclusions}

The present findings provide information for developing comprehensive BI-based needs interventions and preparing targeted health-management programs for breast cancer patients. A comprehensive intervention considering needs, BI, and socio-demographics (e.g., an individualized multimodal supporting program) is recommended to improve HRQoL among women with breast cancer in the post-surgery period.

\begin{abstract}
Abbreviations
AGFI: adjusted goodness-of-fit index; BCS: breast-cancer-specific additional concerns; BI: Body image; BI-AC: BI-related arm change; BI-BC: BI-related behavior change; BI-SAC: BI-related sexual activity change; BI-SC: BI-related social change; BI-SCo: BI-related self-cognition; BI-PC: BI-related psychological change; BI-RC: BI-related role change; BISQ-BC: Body Image Self-Rating Questionnaire for Breast Cancer; BP: bodily pain; EWB: emotional well-being; FACT-Bv4.0: Functional Assessment of Cancer Therapy-Breast version 4.0; FWB: Functional well-being; GFI: Goodness-of-fit index; GH: General health; HRQoL: Health-related quality of life; INF: Information needs; MCS: Mental component summary; MH: Mental health; NC: Normed chi-square; NI: Needs importance; NS: Needs satisfaction; NSQ-BC: Needs Self-Rating Questionnaire for Breast Cancer; PCS: Physical component summary; PF: Physical function; PHY: Physical needs; PSY: Psychological needs; PWB: Physical well-being; RE: Role-emotional; REH: Rehabilitation needs; RMSEA: Root mean square error of approximation; RP: Role-physical; RSE: Respect/self-esteem needs; SEM: Structural equation modeling; SF: Social function; SF-36v2: 36-item Short Form Health Survey version 2; SWB: Social/family well-being; VT: Vitality
\end{abstract}

\section{Acknowledgements}

We wish to thank the National Natural Science Foundation of China (grant no. 81502700) for the funding they provided.

\section{Authors' contributions}

$K Z, J L$ and $X L$ designed the study. $W W, M L, J A, L H$, and $X H$ collected the data. $\mathrm{KZ}$ analyzed and interpreted the data, and prepared the manuscript draft. $K Z, J L$, and $X L$ revised the manuscript. All authors read and approved the final manuscript.

\section{Funding}

The study was supported by the National Natural Science Foundation of China (grant no. 81502700).

\section{Availability of data and materials}

All data generated or analyzed during this study are included in this manuscript.

\section{Ethics approval and consent to participate}

The study protocol was approved by the Biomedical Ethics Committee of Xi'an Jiaotong University Health Science Center (Reference No.: 2015-170). Informed consent was obtained from all participants in the study.

\section{Consent for publication}

Not applicable.

\section{Competing interests}

The authors declare that they have no competing interests.

Received: 12 June 2019 Accepted: 7 May 2020

Published online: 01 June 2020

\section{References}

1. Slowik AJ, Jablonski MJ, Michalowska-Kaczmarczyk AM, Jach R. Evaluation of quality of life in women with breast cancer, with particular emphasis on sexual satisfaction, future perspectives and body image, depending on the method of surgery. Psychiatr Pol. 2017:51:871-88.

2. Bouya S, Koochakzai M, Rafiemanesh H, Balouchi A, Taheri S, Badakhsh M, et al. Health-related quality of life of Iranian breast cancer patients: a metaanalysis and systematic review. Breast Cancer Res Treat. 2018;170:205-12.

3. Doyal L, Gough I. A theory of human need. London: Palgrave; 1991.

4. de Morais FD, Freitas-Junior R, Rahal RM, Gonzaga CM. Sociodemographic and clinical factors affecting body image, sexual function and sexual satisfaction in women with breast cancer. J Clin Nurs. 2016;25:1557-65.

5. Chow KM, Hung KL, Yeung SM. Body image and quality of life among breast cancer survivors: a literature review. World J Oncol. 2016;3:12-20.

6. McClelland SI, Holland KJ, Griggs JJ. Quality of life and metastatic breast cancer: the role of body image, disease site, and time since diagnosis. Qual Life Res. 2015;24:2939-43.

7. Yan H. Medical statistics. 3rd ed. Beijing, China: People's Medical Publishing House; 2015.

8. Ware JE Jr, Kosinski M, Bjorner JB, Turner-Bowker DM, Gandek B, Maruish ME. SF-36v2 ${ }^{-}$health survey: a primer for healthcare providers. Lincoln, Rl: QualityMetric Incorporated; 2008.

9. Ware JE Jr, Kosinski M, Bjorner JB, Turner-Bowker DM, Gandek B, Maruish ME. SF-36v ${ }^{\oplus}$ health survey: administration guide for clinical trial investigators. Lincoln, RI: QualityMetric Incorporated; 2008.

10. Wan C, Zhang D, Yang Z, Tu X, Tang W, Feng C, et al. Validation of the simplified Chinese version of the FACT-B for measuring quality of life for patients with breast cancer. Breast Cancer Res Treat. 2007;106:413-8.

11. Brady MJ, Cella DF, Mo F, Bonomi AE, Tulsky DS, Lloyd SR, et al. Reliability and validity of the functional assessment of cancer therapy-breast qualityof-life instrument. J Clin Oncol. 1997;15:974-86.

12. Zhou K, He X, Huo L, An J, Li M, Wang W, et al. Development of the body image self-rating questionnaire for breast cancer (BISQ-BC) for Chinese mainland patients. BMC Cancer. 2018;18:19.

13. Zhou K, Wang D, Li H, Wei X, Yin J, Liang P, et al. Bidirectional relationships between retention and health-related quality of life in Chinese mainland patients receiving methadone maintenance treatment. PLoS One. 2017;12: e0179009.

14. Zhou K, Huo L, He X, Li M, An J, Wang W, et al. The needs self-rating questionnaire for breast Cancer (NSQ-BC): development of a tool for the needs assessment of women with breast cancer in mainland China. J Eval Clin Pract. 2019:25:889-95.

15. Wu M. Structural equation modeling: AMOS operation and application. 2nd ed. Chongqing, China: Chongqing University Press; 2010.

16. Zhang P. Statistical analysis based on bootstrap method. J Yibin Univ. 2011; 11:31-3.

17. Baron RM, Kenny DA. The moderator-mediator variable distinction in social psychological research: conceptual, strategic, and statistical consideration. J Pers Soc Psychol. 1986;51:1173-82.

18. Ellegaard MB, Grau C, Zachariae R, Bonde JA. Fear of cancer recurrence and unmet needs among breast cancer survivors in the first five years. A crosssectional study. Acta Oncol. 2017;56:314-20.

19. Wang S, Li Y, Li C, Qiao Y, He S. Distribution and determinants of unmet need for supportive care among women with breast cancer in China. Med Sci Monit. 2018;24:1680-7.

20. Balneaves $L G$, Panagiotoglou D, Brazier AS, Lambert LK, Porcino A, Forbes $M$ et al. Qualitative assessment of information and decision support needs for managing menopausal symptoms after breast cancer. Support Care Cancer. 2016;24:4567-75.

21. Edib Z, Kumarasamy V, Binti Abdullah N, Rizal AM, Al-Dubai SAR. Most prevalent unmet supportive care needs and quality of life of breast cancer patients in a tertiary hospital in Malaysia. Health Qual Life Outcomes. 2016;14:26.

22. Hummel SB, van Lankveld JJDM, Oldenburg HSA, Hahn DEE, Kieffer JM, Gerritsma MA, et al. Internet-based cognitive behavioral therapy realizes 
long-term improvement in the sexual functioning and body image of breast cancer survivors. J Sex Marital Ther. 2018;44:485-96.

23. Notari SC, Notari L, Favez N, Delaloye JF, Ghisletta P. The protective effects of a satisfying romantic relationship on women's body image after breast cancer: a longitudinal study. Psychooncology. 2017;26:836-42.

24. Jarkovský J, Skřivanová K, Benešová K, Šnajdrová L, Gregor J, Peterková H, et al. Predictors of quality of life in Czech female breast cancer survivors following treatment with special interest to coping strategies. Vnitr Lek. 2017;63:389-96.

\section{Publisher's Note}

Springer Nature remains neutral with regard to jurisdictional claims in published maps and institutional affiliations.

Ready to submit your research? Choose BMC and benefit from:

- fast, convenient online submission

- thorough peer review by experienced researchers in your field

- rapid publication on acceptance

- support for research data, including large and complex data types

- gold Open Access which fosters wider collaboration and increased citations

- maximum visibility for your research: over $100 \mathrm{M}$ website views per year

At $\mathrm{BMC}$, research is always in progress.

Learn more biomedcentral.com/submissions 